\title{
Eutectic Salt Catalyzed Environmentally Benign and Highly Efficient Biginelli Reaction
}

\author{
Najmadin Azizi, ${ }^{1}$ Sahar Dezfuli, ${ }^{2}$ and Mohmmad Mahmoodi Hahsemi² \\ ${ }^{1}$ Chemistry \& Chemical Engineering Research Center of Iran, P.O. Box 14335-186, Tehran 1496813151, Iran \\ ${ }^{2}$ Department of Chemistry, Science and Research Branch, Islamic Azad University, Tehran, Iran \\ Correspondence should be addressed to Najmadin Azizi, azizi@ccerci.ac.ir
}

Received 8 October 2011; Accepted 21 November 2011

Academic Editors: V. Capriati and R. A. Fernandes

Copyright (C) 2012 Najmadin Azizi et al. This is an open access article distributed under the Creative Commons Attribution License, which permits unrestricted use, distribution, and reproduction in any medium, provided the original work is properly cited.

\begin{abstract}
A simple deep eutectic solvent based on tin (II) chloride was used as a dual catalyst and environmentally benign reaction medium for an efficient synthesis of 3,4-dihydropyrimidin-2(1H)-one derivatives, from aromatic and aliphatic aldehydes, 1,3-dicarbonyl compounds, and urea in good-to-excellent yields and short reaction time. This simple ammonium deep eutectic solvent, easily synthesized from choline chloride and tin chloride, is relatively inexpensive and recyclable, making it applicable for industrial applications.
\end{abstract}

\section{Introduction}

In recent years, utilization of room-temperature ionic liquids (RTILs) in organic synthesis and industry has received great attention due to their unusual properties compared with traditional molecular solvents, such as undetectable vapor pressure, wide liquid temperature range, special solubility for many organic or inorganic compounds, and favorable environments. A closely related class of solvents with physical properties and phase behaviors very similar to those of RTILs are room-temperature deep eutectic solvents (DESs), which were developed by Abbott and coworkers. These eutectic mixtures are attractive alternatives to RTILs, as DESs can be less expensive, more synthetically accessible, nontoxic, and biodegradable [1-4].

The Biginelli reaction is an important and one-pot, multicomponent domino reaction, which allows easy access to Polyfunctionalized dihydropyrimidinones (DHPMs) in an environmentally benign and atom-economic fashion of an aldehyde, urea, and a $\beta$-ketoester under strongly acidic conditions [5-8]. In recent years, dihydropyrimidinones and their derivatives occupy an important place in the realm of natural and synthetic organic chemistry because of their biological activities such as antiviral, antitumor, antibacterial, and anti-inflammatory properties. In addition, these compounds have emerged as potent calcium channel blockers, therapeutic and pharmacological properties (Figure 1) [9-12].

Due to their several applications in the biology and medical chemistry, considerable interest in this transformation has steadily increased over the past decade and several improved procedures have recently been reported [13-47]. However, some of the methods employed for DHPM synthesis have drawbacks, for example, the use of strongly acidic conditions, the use of protic acids, prolonged reaction times, low-to-moderate yields, and organic solvent.

\section{Materials and Methods}

2.1. Chemicals. Reactions were monitored by TLC and GC. FT-IR spectra were recorded using $\mathrm{KBr}$ disks on a Bruker Vector 22 FT-IR Spectrometer, ${ }^{1} \mathrm{H}$ NMR spectra were recorded on $500 \mathrm{MHz}$ NMR spectrometer, and ${ }^{13} \mathrm{C}$ NMR spectra were recorded on $125 \mathrm{MHz}$ NMR spectrometer, respectively, using $\mathrm{CDCl}_{3}$ or DMSO, as a solvent. Chemical shifts have been expressed in ppm downfield from TMS. Melting points were recorded on Buchi 535 melting point apparatus and are uncorrected. All starting materials and choline chloride and Tin chloride are commercially available 
<smiles>CC1=C(C(=O)OC(C)C)C(c2cccc([N+](=O)[O-])c2)N(C(N)=O)C(=O)N1</smiles>

Sq 32926<smiles>CCOC(=O)C1=C(C)NC(=S)NC1c1cccc(O)c1</smiles>

Monastrol<smiles>CC1=C(C(=O)Nc2ccccc2Cl)C(c2cccc([N+](=O)[O-])c2)NC(=O)N1</smiles>

DPPH antioxidant activity

FIGURE 1: Some biologically active dihydropyrimidinones derivatives.<smiles>CCOC(=O)CC(C)=O</smiles><smiles>NC(N)=O</smiles><smiles>CCOC(=O)C1=C(C)NC(=O)NC1c1ccccc1</smiles>

\begin{tabular}{cccccc}
\hline DES & $\mathrm{Ch} / \mathrm{SnCl}_{2}$ & $\mathrm{Ch} / \mathrm{Urea}$ & $\mathrm{Ch} / \mathrm{ZnCl}_{2}$ & $\mathrm{Ch} / \mathrm{ZnCl}_{2} / \mathrm{SnCl}_{2}$ & $\mathrm{Ch} / \mathrm{Gly}$ \\
Molar ratio & $1: 2$ & $1: 2$ & $1: 2$ & $1: 1: 1$ & $1: 3$ \\
Yields (\%) & 95 & 25 & 80 & 90 & 10 \\
\hline
\end{tabular}

Scheme 1: Optimization of reaction condition.

and were purchased and used without further purification. Water and other solvent were distilled before used.

2.1.1. Preparation of Deep Eutectic Solvent. The general route for the synthesis of the ionic liquids was as follows: choline chloride $(100 \mathrm{mmol})$ was mixed with tin chloride $(200 \mathrm{mmol})$ and heated to $\mathrm{ca} .100^{\circ} \mathrm{C}$ in air with stirring until a clear colourless liquid was obtained.

2.1.2. General Procedure. A mixture of benzaldehyde (3 mmol), urea (3 mmol), and methyl acetoacetate $(3 \mathrm{mmol})$ in tin (II) chloride-choline chloride $(2: 1)(0.1 \mathrm{~mL})$ ionic liquid was added into a test tube with a magnetic stirring bar under $\mathrm{N}_{2}$ atmosphere. The test tube was heated in an oil bath at $100^{\circ} \mathrm{C}$ for 30 minutes and then was cooled to room temperature slowly, and ethyl acetate and in some cases ethanol $(10 \mathrm{~mL})$ was added slowly and filtered off to extract the product from the deep eutectic solvent. For most of the reactions, purification was not necessary and the products were analyzed by ${ }^{1} \mathrm{H}$ NMR spectroscopy and melting point; however, appropriate recrystallization in hot ethanol was used for further purification. All compounds were known and were characterized on the basis of their spectroscopic data (IR, NMR) and melting point by comparison with those reported in the literature.

\section{Results and Discussion}

During the course of our study aiming at improving the ecocompatibility of certain organic processes, we have been particularly interested in the development of organic transformations in a purely aqueous system to develop environmentally benign reactions [48-57]. Herein, we wish to report deep eutectic solvent as a novel catalyst and reaction medium for an efficient preparation of 3,4-dihydropyrimidinones under mild reaction conditions with short reaction time and simple work-up. 
TABLE 1: $\left(\mathrm{SnCl}_{2}\right)_{2} \mathrm{ChCl}$ catalyzed green synthesis of dihydropyrimidinons.<smiles>[R]C(=O)CC([R])=O</smiles><smiles>NC(N)=O</smiles>

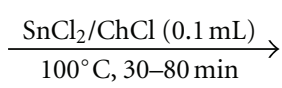<smiles>[R]C(=O)C1=C([R])NC(=O)NC1[R]</smiles>

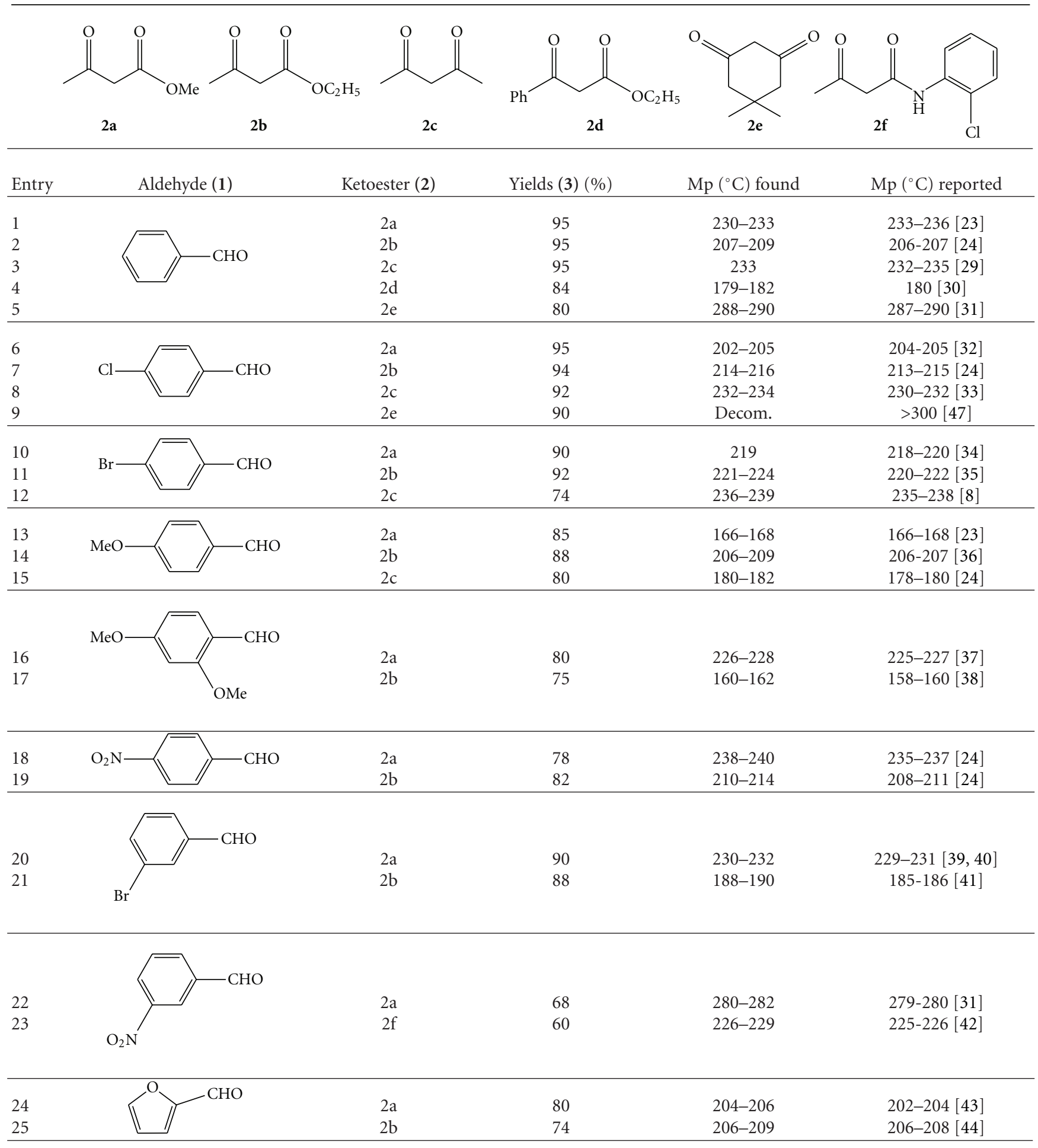


Table 1: Continued.

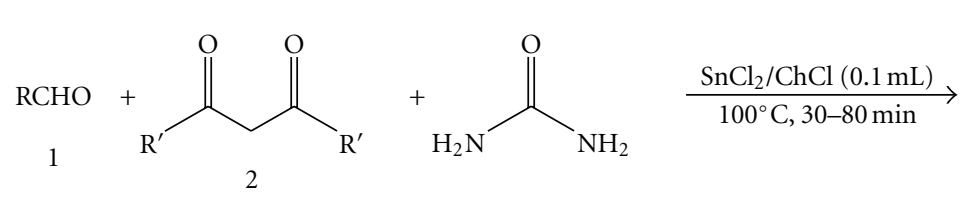<smiles>[R]C(=O)C1=C([R])NC(=O)NC1[R]</smiles>

(252)

In an initial experiment, benzaldehyde ( $1 \mathrm{mmol})$ was treated with urea $(1 \mathrm{mmol})$ and ethyl acetoacetate $(1 \mathrm{mmol})$ in five choline-based deep eutectic solvents at different re-action condition. First findings indicated that, Tin chloride/choline-chloride- $\left(\mathrm{ChCl} / \mathrm{SnCl}_{2}-\right)$ based deep eutectic sol-vent $(0.1 \mathrm{~mL})$ at $100^{\circ} \mathrm{C}$ was an excellent reaction condition and dihydropyrimidinones (DHPMs) 3 were obtained in 95\% yield in $30 \mathrm{~min}$ (Scheme 1). Other chlorinebased ionic liquids such as urea/choline chloride, polyethylene/choline chloride, zinc chloride/choline chloride drive the desired products in low yields.

Under optimized reaction conditions, a broad range of structurally diverse 1,3-dicarbonyl compounds such as ethylacetoacetate (2a), methylacetoacetate (2b), pentane-2,4dione (2c), ethyl 3-oxo-3-phenylpropanoate, (2d) 5,5dimethyl-1,3-Cyclohexanedione (2e), 3-oxo-N-(2-chlorophenyl)butanamide (2f), aromatic and aliphatic aldehydes, and urea are subjected to this green procedure to produce the corresponding dihydropyrimidinones not only in good yield but also with higher reaction rates (Table 1). A wide variation of alkyl groups and sensitive functionalities such as $\mathrm{NO}_{2}, \mathrm{Cl}, \mathrm{OH}, \mathrm{OMe}$, and heterocyclic moieties in 1,3dicarbonyl compound as well as in aldehyde are tolerated in this procedure to provide a library of dihydropyrimidinones with a variety of substituents.
In general, the reactions are very clean, and no side product was obtained in any run. In fact, the crude products obtained are of high purity and do not require any chromatographic separation in most cases. Recrystallization from hot ethanol provides analytically pure sample. Furthermore, deep eutectic solvent was recycled and reused for four times without any loss of activity.

\section{Conclusion}

This work describes the one-pot, three-component procedure of the synthesis of dihydropyrimidin-2(1H)-ones in deep eutectic solvent that provides an efficient and practical modification of Biginelli reaction. The separation and purification process are very simple and convenient, only needing recrystallization. Starting materials are inexpensive and commercially available. Moreover, this method offers several advantages including high yields, short reaction times, and a simple work-up procedure, and it also has the ability to tolerate a wide variety of substitutions in all three components, which is lacking in existing procedure.

\section{Acknowledgment}

Financial support of this work by Chemistry and Chemical Research Center of Iran is gratefully appreciated. 


\section{References}

[1] A. P. Abbott, G. Capper, D. L. Davies, R. K. Rasheed, and V. Tambyrajah, "Novel solvent properties of choline chloride/urea mixtures," Chemical Communications, vol. 9, no. 1, pp. 70-71, 2003.

[2] A. P. Abbott, G. Capper, D. L. Davies, and R. Rasheed, "Ionic liquids based upon metal halide/substituted quaternary ammonium salt mixtures," Inorganic Chemistry, vol. 43, no. 11, pp. 3447-3452, 2004.

[3] Z. Chen, B. Zhou, H. Cai, W. Zhu, and X. Zou, "Simple and efficient methods for selective preparation of $\alpha$-mono or $\alpha, \alpha$ dichloro ketones and $\beta$-ketoesters by using DCDMH," Green Chemistry, vol. 11, no. 2, pp. 275-278, 2009.

[4] Z. Chen, W. Zhu, Z. Zheng, and X. Zou, "One-pot $\alpha$ nucleophilic fluorination of acetophenones in a deep eutectic solvent," Journal of Fluorine Chemistry, vol. 131, no. 3, pp. 340 344, 2010.

[5] P. Biginelli, "Derivati Aldeiduredici Degli Eteri Acetile DossalAcetico," Gazzetta Chimica Italiana, vol. 23, pp. 360-416, 1893.

[6] A. Dondoni and A. Massi, "Design and synthesis of new classes of heterocyclic C-glycoconjugates and carbon-linked sugar and heterocyclic amino acids by Asymmetric Multicomponent Reactions (AMCRs)," Accounts of Chemical Research, vol. 39, no. 7, pp. 451-463, 2006.

[7] C. O. Kappe, "The Biginelli Reaction," in Multicomponent Reactions, J. Zhu and H. Bienaymq, Eds., p. 95, Wiley, Weinheim, Germany, 2005.

[8] C. O. Kappe, "4-Aryldihydropyrimidines via the Biginelli condensation: Aza-analogs of nifedipine-type calcium channel modulators," Molecules, vol. 3, no. 1, pp. 1-9, 1998.

[9] K. S. Atwal, B. N. Swanson, S. E. Unger et al., "Dihydropyrimidine calcium channel blockers. 3. 3-Carbamoyl-4-aryl-1,2,3,4tetrahydro-6-methyl-5-pyrimidinecarboxylic acid esters as orally effective antihypertensive agents," Journal of Medicinal Chemistry, vol. 34, no. 2, pp. 806-811, 1991.

[10] V. Summa, A. Petrocchi, V. G. Matassa et al., “4,5dihydroxypyrimidine carboxamides and $\mathrm{N}$-alkyl-5-hydroxypyrimidinone carboxamides are potent, selective HIV integrase inhibitors with good pharmacokinetic profiles in preclinical species," Journal of Medicinal Chemistry, vol. 49, no. 23, pp. 6646-6649, 2006.

[11] G. C. Rovnyak, S. D. Kimball, B. Beyer et al., "Calcium entry blockers and activators: conformational and structural determinants of dihydropyrimidine calcium channel modulators," Journal of Medicinal Chemistry, vol. 38, no. 1, pp. 119-129, 1995.

[12] H. Y. K. Kaan, V. Ulaganathan, O. Rath et al., "Structural basis for inhibition of Eg5 by dihydropyrimidines: stereoselectivity of antimitotic inhibitors enastron, dimethylenastron and fluorastrol," Journal of Medicinal Chemistry, vol. 53, no. 15, pp. 5676-5683, 2010.

[13] G. B. D. Rao, B. N. Acharya, S. K. Verma, and M. P. Kaushik, "N,N'-Dichlorobis(2,4,6-trichlorophenyl)urea (CC2) as a new reagent for the synthesis of pyrimidone and pyrimidine derivatives via Biginelli reaction," Tetrahedron Letters, vol. 52, no. 7, pp. 809-812, 2011.

[14] K. K. Pasunooti, H. Chai, C. N. Jensen, B. K. Gorityala, S. Wang, and X. W. Liu, "A microwave-assisted, copper-catalyzed three-component synthesis of dihydropyrimidinones under mild conditions," Tetrahedron Letters, vol. 52, no. 1, pp. 80-84, 2011.
[15] G. Garima, V. P. Srivastava, and L. D. S. Yadav, "Biginelli reaction starting directly from alcohols," Tetrahedron Letters, vol. 51, no. 49, pp. 6436-6438, 2010.

[16] Y. Y. Wu, Z. Chai, X. Y. Liu, G. Zhao, and S. W. Wang, "Synthesis of substituted 5-(pyrrolidin-2-yl)tetrazoles and their application in the asymmetric Biginelli reaction," European Journal of Organic Chemistry, no. 6, pp. 904-911, 2009.

[17] K. Singh and K. Singh, "Magnesium/methanol: an effective reducing agent for chemoselective reduction of pyrimidine2(1H)-ones," Tetrahedron Letters, vol. 50, no. 19, pp. 22192221, 2009.

[18] D. Ding and C. G. Zhao, "Primary amine catalyzed Biginelli reaction for the enantioselective synthesis of 3,4dihydropyrimidin-2(1H)-ones," European Journal of Organic Chemistry, no. 20, pp. 3802-3805, 2010.

[19] V. Polshettiwar and R. S. Varma, "Biginelli reaction in aqueous medium: a greener and sustainable approach to substituted 3,4-dihydropyrimidin-2(1H)-ones," Tetrahedron Letters, vol. 48, no. 41, pp. 7343-7346, 2007.

[20] X. H. Chen, X. Y. Xu, H. Liu, L. F. Cun, and L. Z. Gong, "Highly enantioselective organocatalytic Biginelli reaction," Journal of the American Chemical Society, vol. 128, no. 46, pp. 1480214803, 2006.

[21] O. M. Singh and N. S. Devi, "Application of $\beta$-Oxodithioesters in domino and multicomponent reactions: Facile route to dihydropyrimidines and coumarins," Journal of Organic Chemistry, vol. 74, no. 8, pp. 3141-3144, 2009.

[22] Y. Wang, J. Yu, Z. Miao, and R. Chen, "Bifunctional primary amine-thiourea-TfOH (BPAT-TfOH) as a chiral phasetransfer catalyst: the asymmetric synthesis of dihydropyrimidines," Organic and Biomolecular Chemistry, vol. 9, no. 8, pp. 3050-3054, 2011.

[23] H. Murata, H. Ishitani, and M. Iwamoto, "Synthesis of Biginelli dihydropyrimidinone derivatives with various substituents on aluminium-planted mesoporous silica catalyst," Organic and Biomolecular Chemistry, vol. 8, no. 5, pp. 12021211, 2010.

[24] B. C. Ranu, A. Hajra, and U. Jana, "Indium(III) chloridecatalyzed one-pot synthesis of dihydropyrimidinones by a three-component coupling of 1,3-dicarbonyl compounds, aldehydes, and urea: an improved procedure for the Biginelli reaction," Journal of Organic Chemistry, vol. 65, no. 19, pp. 6270-6272, 2000.

[25] Y. Ma, C. Qian, L. Wang, and M. Yang, "Lanthanide triflate catalyzed biginelli reaction. One-pot synthesis of dihydropyrimidinones under solvent-free conditions," Journal of Organic Chemistry, vol. 65, no. 12, pp. 3864-3868, 2000.

[26] X. Han, F. Xu, Y. Luo, and Q. Shen, "An efficient one-pot synthesis of dihydropyrimidinones by a samarium diiodide catalyzed biginelli reaction under solvent-free conditions," European Journal of Organic Chemistry, no. 8, pp. 1500-1503, 2005.

[27] W. Su, J. Li, Z. Zheng, and Y. Shen, "One-pot synthesis of dihydropyrimidiones catalyzed by strontium(II) triflate under solvent-free conditions," Tetrahedron Letters, vol. 46, no. 36, pp. 6037-6040, 2005.

[28] Y. Huarig, F. Yang, and C. Zhu, "Highly enantioselective Biginelli reaction using a new chiral ytterbium catalyst: asymmetric synthesis of dihydropyrimidines," Journal of the American Chemical Society, vol. 127, no. 47, pp. 16386-16387, 2005.

[29] D. Prodius, F. Macaev, V. Mereacre et al., "Synthesis and characterization of $\mathrm{Fe} 2 \mathrm{CuO}$ clusters as precursors for nanosized 
catalytic system for Biginelli reaction," Inorganic Chemistry Communications, vol. 12, no. 7, pp. 642-645, 2009.

[30] A. Shaabani, A. Bazgir, and F. Teimouri, "Ammonium chloride-catalyzed one-pot synthesis of 3,4-dihydropyrimidin-2- $(1 \mathrm{H})$-ones under solvent-free conditions," Tetrahedron Letters, vol. 44, no. 4, pp. 857-859, 2003.

[31] S. V. Ryabukhin, A. S. Plaskon, S. S. Bondarenko et al., "Acyl pyruvates as synthons in the Biginelli reaction," Tetrahedron Letters, vol. 51, no. 32, pp. 4229-4232, 2010.

[32] A. Shaabani, A. Sarvary, A. Rahmati, and A. H. Rezayan, "Ionic liquid/silica sulfuric acid promoted fast synthesis of a Biginelli-like scaffold reaction," Letters in Organic Chemistry, vol. 4, no. 1, pp. 68-71, 2007.

[33] H. N. Karade, M. Sathe, and M. P. Kaushik, "Synthesis of 4-aryl substituted 3,4-dihydropyrimidinones using silicachloride under solvent free conditions," Molecules, vol. 12, no. 7, pp. 1341-1351, 2007.

[34] M. Yarim, S. Saraç, M. Ertan, O. Batu, and K. Erol, "Synthesis, structural elucidation and pharmacological properties of some 5-acetyl-3,4-dihydro-6-methyl-4-(substituted phenyl)-2(1H)pyrimidinones," Farmaco, vol. 54, no. 6, pp. 359-363, 1999.

[35] G. Aridoss and Y. T. Jeong, "A convenient one-pot Biginelli reaction catalyzed by $\mathrm{Y}(\mathrm{OAc}) 3$ : an improved protocol for the synthesis of 3,4-dihydropyrimidin-2(1H)-ones and their sulfur analogues," Bulletin of the Korean Chemical Society, vol. 31, no. 4, pp. 863-868, 2010.

[36] J. Wannberg, D. Dallinger, C. O. Kappe, and M. Larhed, "Microwave-enhanced and metal-catalyzed functionalizations of the 4-aryl-dihydropyrimidone template," Journal of Combinatorial Chemistry, vol. 7, no. 4, pp. 574-583, 2005.

[37] F. L. Zumpe, M. Flüß, K. Schmitz, and A. Lender, "Propane phosphonic acid anhydride: a new promoter for the onepot Biginelli synthesis of 3,4-dihydropyrimidin-2(1H)-ones," Tetrahedron Letters, vol. 48, no. 8, pp. 1421-1423, 2007.

[38] D. S. Bose, L. Fatima, and H. B. Mereyala, "Green chemistry approaches to the synthesis of 5-alkoxycarbonyl-4aryl-3,4-dihydropyrimidin-2(1H)-ones by a three-component coupling of one-pot condensation reaction: Comparison of ethanol, water, and solvent-free conditions," Journal of Organic Chemistry, vol. 68, no. 2, pp. 587-590, 2003.

[39] K. Ananda Kumar, M. Kasthuraiah, C. Suresh Reddy, and C. Devendranath Reddy, "Mn $(\mathrm{OAc})_{3} \cdot{ }_{2} \mathrm{H}_{2} \mathrm{O}$-mediated threecomponent, one-pot, condensation reaction: an efficient synthesis of 4-aryl-substituted 3,4-dihydropyrimidin-2-ones," Tetrahedron Letters, vol. 42, no. 44, pp. 7873-7875, 2001.

[40] X. Fan, X. Zhang, and Y. Zhang, "Samarium chloride catalysed Biginelli reaction: one-pot synthesis of 3,4-dihydropyrimidin2(1h)-ones," Journal of Chemical Research S, no. 9, pp. 436438, 2002.

[41] A. S. Paraskar, G. K. Dewkar, and A. Sudalai, "Cu(OTf)2: a reusable catalyst for high-yield synthesis of 3,4dihydropyrimidin-2(1H)-ones," Tetrahedron Letters, vol. 44, no. 16, pp. 3305-3308, 2003.

[42] J. Lu and Y. Bai, "Catalysis of the Biginelli reaction by ferric and nickel chloride hexahydrates. One-pot synthesis of 3,4dihydropyrimidin-2(1H)-ones," Synthesis, no. 4, pp. 466-470, 2002.

[43] F. Bigi, S. Carloni, B. Frullanti, R. Maggi, and G. Sartori, "A revision of the biginelli reaction under solid acid catalysis. Solvent-free synthesis of dihydropyrimidines over montmorillonite KSF," Tetrahedron Letters, vol. 40, no. 17, pp. 3465-3468, 1999.
[44] J. T. Li, J. F. Han, J. H. Yang, and T. S. Li, "An efficient synthesis of 3,4-dihydropyrimidin-2-ones catalyzed by $\mathrm{NH}_{2} \mathrm{SO}_{3} \mathrm{H}$ under ultrasound irradiation," Ultrasonics Sonochemistry, vol. 10, no. 3, pp. 119-122, 2003.

[45] S. Tu, F. Fang, C. Miao et al., "One-pot synthesis of 3,4dihydropyrimidin-2(1H)-ones using boric acid as catalyst," Tetrahedron Letters, vol. 44, no. 32, pp. 6153-6155, 2003.

[46] G. Sabitha, G. S. K. K. Reddy, K. B. Reddy, and J. S. Yadav, "Vanadium(III) chloride catalyzed Biginelli condensation: Solution phase library generation of dihydropyrimidin- $(2 \mathrm{H})$ ones," Tetrahedron Letters, vol. 44, no. 34, pp. 6497-6499, 2003.

[47] K. S. Niralwad, B. B. Shingate, and M. S. Shingare, "Ultrasound-assisted one-pot synthesis of octahydroquinazolinone derivatives catalyzed by acidic ionic liquid [tbmim $] \mathrm{Cl}_{2} / \mathrm{AlCl}_{3}$," Journal of the Chinese Chemical Society, vol. 57, no. 1, pp. 89-92, 2010.

[48] N. Azizi, B. Pourhasan, F. Aryanasab, and M. R. Saidi, "A simple and novel eco-friendly process for the one-pot synthesis of dithiocarbamates from amines, carbon disulfide, and epoxides," Synlett, no. 8, pp. 1239-1242, 2007.

[49] N. Azizi, F. Aryanasab, L. Torkiyan, A. Ziyaei, and M. R. Saidi, "One-pot synthesis of dithiocarbamates accelerated in water," Journal of Organic Chemistry, vol. 71, no. 9, pp. 3634-3635, 2006.

[50] N. Azizi, F. Aryanasab, and M. R. Saidi, "Straightforward and highly efficient catalyst-free one-pot synthesis of dithiocarbamates under solvent-free conditions," Organic Letters, vol. 8, no. 23, pp. 5275-5277, 2006.

[51] N. Azizi, F. Ebrahimi, E. Aakbari, F. Aryanasab, and M. R. Saidi, "Waste-free and environment-friendly uncatalyzed synthesis of dithiocarbamates under solvent-free conditions," Synlett, no. 18, pp. 2797-2800, 2007.

[52] N. Azizi and M. R. Saidi, "Novel and efficient method for the silylation of hydroxyl groups with Hexamethyldisilazane (HMDS) under solvent-free and neutral conditions," Organometallics, vol. 23, no. 6, pp. 1457-1458, 2004.

[53] N. Azizi and M. R. Saidi, "Highly chemoselective addition of amines to epoxides in water," Organic Letters, vol. 7, no. 17, pp. 3649-3651, 2005.

[54] N. Azizi, F. Arynasab, and M. R. Saidi, "Efficient Friedel-crafts alkylation of indoles and pyrrole with enones and nitroalkene in water," Organic and Biomolecular Chemistry, vol. 4, no. 23, pp. 4275-4277, 2006.

[55] N. Azizi, R. Baghi, H. Ghafuri, M. Bolourtchian, and M. Hashemi, "Silicon tetrachloride catalyzed aza-michael addition of amines to conjugated alkenes under solvent-free conditions," Synlett, no. 3, pp. 379-382, 2010.

[56] N. Azizi, L. Torkiyan, and M. R. Saidi, "Highly efficient onepot three-component Mannich reaction in water catalyzed by heteropoly acids," Organic Letters, vol. 8, no. 10, pp. 20792082, 2006.

[57] N. Azizi, A. Khajeh-Amiri, H. Ghafuri, and M. Bolourtchian, "Toward a practical and waste-free synthesis of thioureas in water," Molecular Diversity, vol. 15, no. 1, pp. 157-161, 2011. 


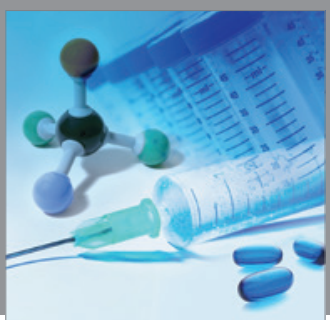

International Journal of

Medicinal Chemistry

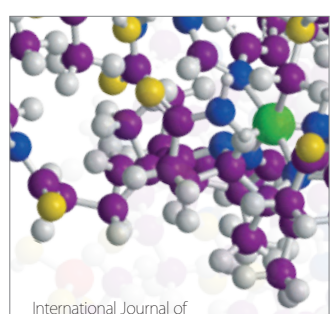

Carbohydrate Chemistry

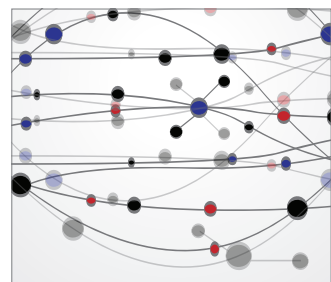

The Scientific World Journal
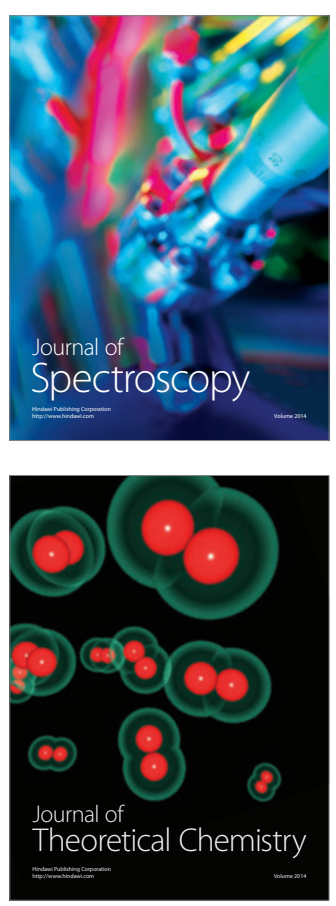
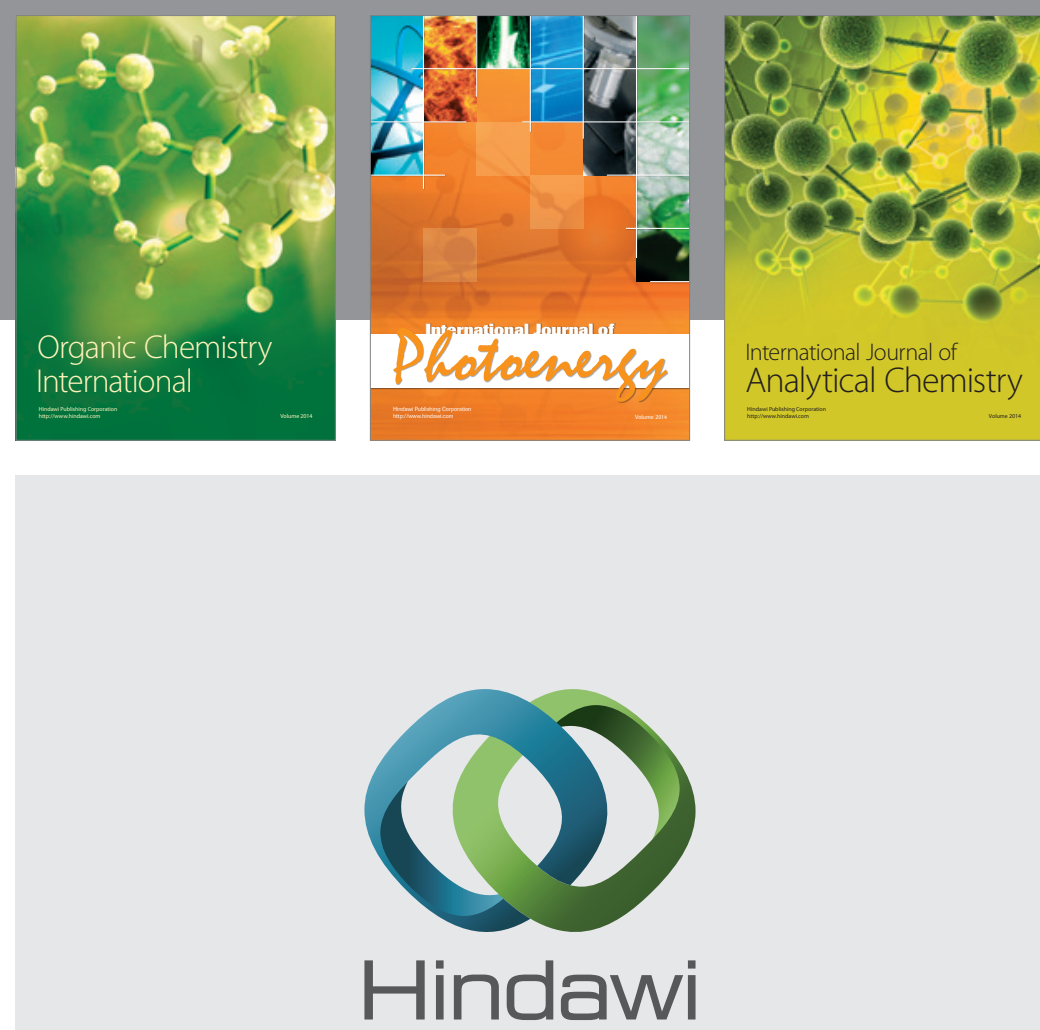

Submit your manuscripts at

http://www.hindawi.com
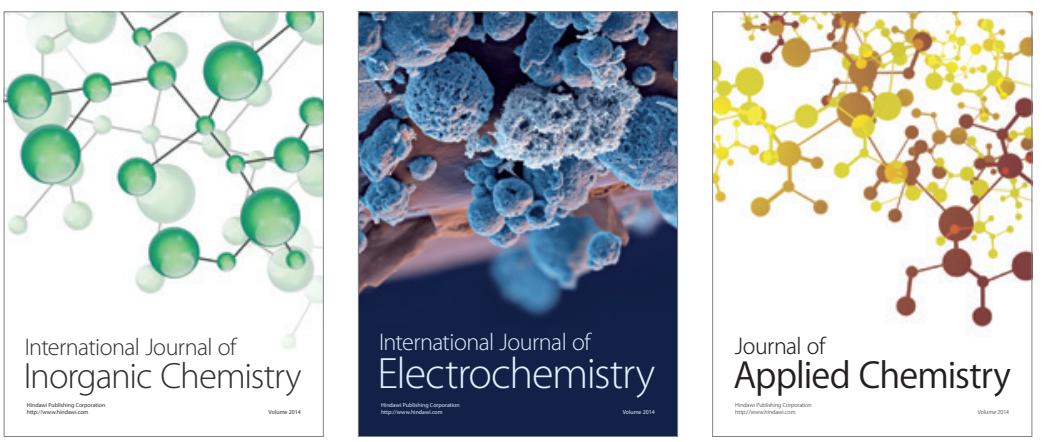

Journal of

Applied Chemistry
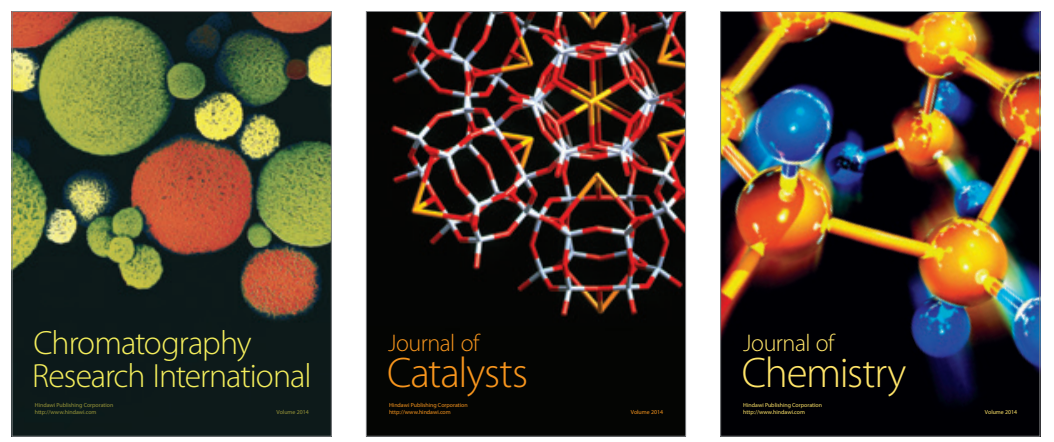
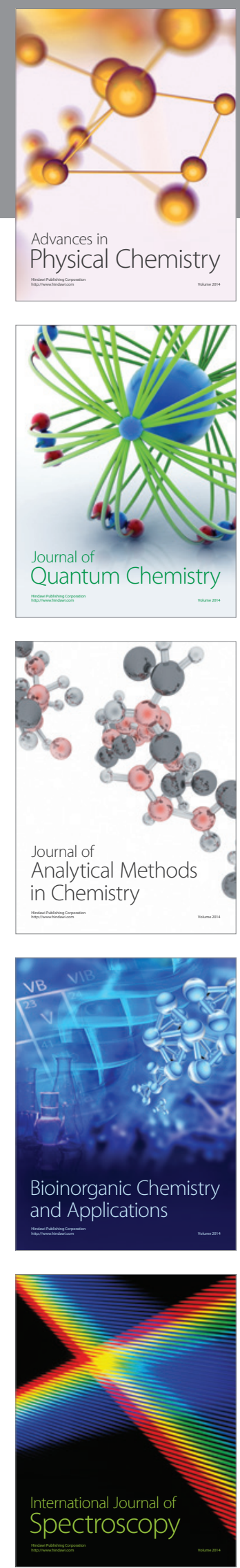